\title{
ISOLASI DAN KARAKTERISASI SENYAWA B-SITOSTEROL DAN \\ FLAVONOID DARI KULIT BATANG AGLAIA ODORATA L
}

\author{
${ }^{1}$ Febri Nur Ngazizah \\ ${ }^{1}$ STIKes Borneo Cendekia Medika Pangkalan Bun \\ ${ }^{1}$ Email: febrinurngazizah@gmail.com
}

\begin{abstract}
Abstrak
Pacar cina (Aglaia odorata Lour) merupakan tanaman yang banyak dimanfaatkan sebagai obat tradisional sehingga berpotensi untuk mengetahui senyawa bahan alam yang dikandungnya. Penelitian ini bertujuan mengisolasi dan mengkarakterisasi senyawa metabolit sekunder dari ektrak kulit batang pacar cina. Metode penelitian ini yaitu dengan cara maserasi dan kromatografi kolom. Sebelum dikolom, perlu dilakukan untuk menentukan pemisahan terbaik setiap fraksi dengan kromatografi lapis tipis (KLT). Fraksi terdiri atas n-heksana, etil asetat dan methanol. Senyawa hasil isolasi dari ekstrak etil asetat dikarakterisasi dengan spektroskopi (UV, IR, ${ }^{1} \mathrm{H}$ $\left.\mathrm{NMR},{ }^{13} \mathrm{C}-\mathrm{NMR}\right)(U V, I R, 1 H-N M R, 13 C-N M R)$ diperoleh dua senyawa yaitu $\beta$ sitosterol dan senyawa golongan flavonoid.
\end{abstract}

Kata kunci : Aglaia odorata L., $\beta$-sitosterol, Flavonoid

ISOLATION AND CHARACTERIZATION OF B-SITOSTEROL AND FLAVONOID COMPOUNDS FROM AGLAIA ODORATA STONE

\section{LEATHER}

\begin{abstract}
ABSTRACK
Chinese girlfriend (Aglaia odorata Lour) is a plant that is widely used as traditional medicine so it has the potential to find out the natural compounds it contains. This study aims to isolate and characterize secondary metabolite compounds from the extracts of Chinese henna stem bark. This research method is by maceration and column chromatography. Before the column, it is necessary to determine the best separation of each fraction by thin layer chromatography (TLC). The fraction consists of n-hexane, ethyl acetate and methanol. Isolated compounds from ethyl acetate extract were characterized by spectroscopy (UV, IR, 1H-NMR, 13C-NMR) (UV, IR, 1H-NMR, 13C-NMR) obtained two compounds namely $\beta$-sitosterol and flavonoid group compounds.
\end{abstract}

Keywords: Aglaia odorata L., $\beta$-sitosterol,Flavonoids 


\section{PENDAHULUAN}

Pacar cina (Aglai odorata L.) merupakan salah satu tanaman dari famili Meliaceae. Daerah penyebaran tumbuhan ini meliputi India, Cina bagian selatan, Laos, Asia Tenggara, Australia bagian utara dan kepulauan di Samudra Pasifik. Di Indonesia tumbuhan ini dapat ditemui tumbuh di pulau Sumatera, Kalimantan, Jawa, Sulawesi, Bali dan Flores (Setiawati, dkk. 2008) . Pacar cina dapat dimanfaatkan sebagai obat tradisional untuk demam, kencing nanah, penyakit kulit, dan obat gatal (sugianto, dkk. 2014). Dengan manfaat yang dikandung tersebut, tentunya pacar cina memiliki senyawa kimia yang berpotensi untuk dilakukan penelitian lebih lanjut.

Beberapa senyawa telah diisolasi dari tanaman Aglaia odorata yaitu 8-(7',8',9'-propanetriol-4' metoksi-3'O-fenilpropanoid) - 7 hidroksi - 6 - metoksi kumarin, A kleomiscosin, asam betulinat, asam alphutolat, 20S,24S-dihidroksidammar-25-en-3-one, Asam ursolat, cabraleahidroksilakton, asam xanthocerasat, 24,25-dihidroksidammar-20-en-3-one, dammar-20-ene3b,24(R),25-triol, sideroksilin, 8demetilsideroksilin, 2'-hidroksi-4,4',6'trimetoksi-calcon, (2R,3R)-(+)-4',5,7trimetoksi dihidroflavonol, naringenin trimetil ether, 2,3-dihidro-5-hidroksi4',7-dimetoksiflavon, odorin, odorinol, dan rokaglaol. (Zhang, 2012 dan Hartanto, 2012)

Berdasarkan laporan yang dikumpulkan pada studi kimia, tanaman pacar cina mengandung alkaloid, saponin, flavonoida, tanin serta minyak atsiri. Selain itu ditemukan rokaglamida yang merupakan senyawa aktif dalam insektisida tanaman (Setiawati, 2012). Pada penelitian sebelumnya untuk tanaman dengan spesies yang sama telah dilakukan oleh Dwi (2015) pada bagian daunnya. maka perlu dilakukan penelitian pada bagian kulit batang pacar cina untuk mengetahui kandungan senyawa lainnya.

\section{METODA PENELITIAN}

Alat

Alat yang digunakan untuk proses isolasi yaitu mortar grinder, seperangkat alat distilasi, rotary evaporator (Heidolph Laborota 4000), lumpang dan alu, kolom kromatografi, plat KLT, neraca analitik, kertas saring, oven,alumunium foil, lampu UV ( $\lambda$ 254 dan $365 \mathrm{~nm}$ ) sebagai pengungkap noda. Untuk mengukur titik leleh digunakan alat Melting Point (Stuart SMP10). Untuk karakterisasi senyawa digunakan spektrofotometer ultraviolet visible (Shimadzu PharmaSpec UV1700), spektrofotometer inframerah (Thermo Scientific Nicolet iS10) dan Spektroskopi NMR.

\section{Bahan}

Bahan-bahan yang digunakan dalam penelitian ini yaitu pelarut teknis (Brataco) yaitu n-heksana, etil asetat dan methanol yang telah didestilasi. Silika gel 60 (0,063-0,200 mm/Merck). Pereaksi uji profil fitokimia, kloroform pa (Merck), asam klorida pa (Merck), serbuk magnesium (Merck) dan besi 
(III) klorida(Merck), asam sulfat $2 \mathrm{~N}$ (Merck), akuades, anhidrida asetat (Merck), plat kromatografi lapis tipis, kertas saring, kloroform (Merck).

\section{Kulit batang Aglaia odorata $\mathbf{L}$}

Kulit batang segar Aglaia odorata $\mathrm{L}(8 \mathrm{~kg})$ yang didapat didaerah Tanjung Puting, Kabupaten Kotawaringin Barat, Indonesia. Tanaman diindetifikasi jenisnya di Laboratorium Herbarium Universitas Jenderal Soedirman, Program Studi Biologi, Fakultas Matematika dan Ilmu Pengetahuan Alam, Universitas Jenderal Soedirman Semarang, Indonesia.Tanaman tersebut dikeringkan selama 5 minggu. Setelah kering, digrinder dengan mortar grinder sampai berbentuk bubuk.

\section{Uji Profil Fitokimia Sampel}

Uji profil fitokimia kandungan metabolit sekunder dilakukan terhadap ekstrak kulit batang Aglaia odorata L. Sebanyak 5 gram sampel dimasukkan dalam tabung reaksi dan diekstrak dengan metanol yang telah dipanaskan diatas nyala spritus selama 5 menit, kemudian disaring dalam keadaan panas. Hasil saringan kemudian ditambahkan air dan kloroforom sama banyak (1:1), lalu dikocok kuat dan dibiarkan selama beberapa saat sampai terbentuk dua lapisan. Lapisan air digunakan untuk uji senyawa flavonoid, fenolik dan saponin. Lapisan kloroforom digunakan untuk uji senyawa terpenoid, steroid, dan alkaloid. (Simes, dkk, 1995).

\section{Preparasi Ekstrak Kulit batang Aglaia odorata L}

Sebanyak $3 \mathrm{~kg}$ bubuk sampel kering dimaserasi selama 3-4 hari dengan 10 L n-heksana. Hasil maserasi disaring dan dipekatkan menggunakan rotary evaporator pada suhu $40^{\circ} \mathrm{C}$ dan diperoleh ekstrak pekat n-heksana. Maserasi dilakukan sampai tujuh kali dan semua ekstrak pekat n-heksana digabung. Ampas maserasi dengan nheksana dilanjutkan maserasi dengan etil asetat selama 3-4 hari dengan $8 \mathrm{~L}$ etil asetat dan dipekatkan. Maserasi dilakukan tujuh kali dan semua ekstrak digabung. Ampas dari maserasi dengan etil asetat dilanjutkan maserasi dengan methanol $8 \mathrm{~L}$ methanol dan dipekatkan. Maserasi dilakukan tiga kali dan semua ekstrak digabung.

\section{Pemurnian Ekstrak Etil Asetat Kulit Batang Aglaia odorata L}

Ekstrak etil asetat yang akan dikolom ditimbang sebanyak $20 \mathrm{~g}$. Kemudian sampel dimasukkan ke dalam lumpang, digerus sedikit demi sedikit dengan silika gel yang telah ditimbang sebanyak 20 g. Sampel digerus hingga berbentuk bubuk dan homogen. Kemudian sampel yang sudah dipreadsorpsi dimasukkan ke dalam kolom. Selanjutnya kolom dielusi dengan pelarut menggunakan metoda isokratik, dengan perbandingan eluen heksana : etil (1 : 9) sebanyak $4200 \mathrm{~mL}$. Hasil dari kromatografi kolom (eluat) ditampung dan dianalisis pola pemisahan nodanya menggunakan kromatografi lapis tipis untuk melihat noda yang sama. Eluat yang mempunyai noda yang sama digabung. 
Hasil penggabungan diperoleh 15 fraksi (A-O).

Dari 15 fraksi, fraksi B diperoleh sebanyak $3 \mathrm{~g}$ yang dilanjutkan proses re-kolom. Hasil rekolom fraksi B diperoleh 3 fraksi (B1-B3). Pada fraksi B2 $(0,423 \mathrm{~g})$ terdapat padatan pada permukaan dalam botol. Kemudian padatan ini dicuci dengan penambahan pelarut $\mathrm{n}$ heksana dan etil asetat sampai diperoleh padatan putih.

\section{Karakterisasi Senyawa $\beta$-sitosterol}

Senyawa $\beta$-sitosterol diuji titik lelehnya dengan melting point apparatus dan dikarakterisasi dengan spektroskopi untuk penetapan struktur diperoleh dengan alat spektrofotometer UV-Vis, FTIR, ${ }^{1} \mathrm{H}$ NMR, dan ${ }^{13} \mathrm{C}$ NMR.

\section{HASIL DAN PEMBAHASAN}

Padatan putih ini dilakukan uji dengan plat KLT diperoleh adanya satu noda setelah diberi pereaksi anhidrida asetat dan asam sulfat, dengan adanya noda berwarna biru kehijauan yang menandakan senyawa $\beta$-sitosterol. Kemudian senyawa tersebut diidentifikasi dan dikarakterisasi.
Fraksi B3 (0,723 g) direkolom dan diperoleh hasil eluat no 21-26, dengan noda yang sama. Kemudian padatan dicuci dengan perlarut $n$ heksana dan etil asetat. Padatan ini dilakukan uji KLT diperoleh adanya satu noda biru pada UV ( $\lambda=365 \mathrm{~nm})$. Padatan ini diuji cyanidin test terbentuk warna merah muda menandakan senyawa golongan flavonoid.

Pada penelitian ini diawali dengan proses isolasi dengan cara maserasi (perendaman) yang dilakukan berulang-ulang dan dipekatkan sehingga didapatkan hasil seperti pada Tabel 1.

\section{Pemurnian Dengan Kromatografi}

Ekstrak etil asetat yang telah diisolasi dengan kromatografi kolom diperoleh dua senyawa yaitu senyawa $\beta$-sitosterol (Kristal berwarna putih) dan senyawa flavonoid (Kristal berwarna putih kekuningan), Kemudian senyawa $\beta$-sitosterol (pada Tabel 2) diuji dengan KLT dan penampakan noda. Pengujian KLT dilakukan dengan berbagai tingkat kepolaran eluen. Hasilnya dimonitoring dengan lampu UV dan pereaksi LiebermanBurchard.

Tabel 1. Hasil maserasi ekstrak dari tingkatan pelarut yang digunakan dan banyak pengulangan yang dilakukan.

\begin{tabular}{ccccc}
\hline Ekstrak & $\begin{array}{c}\text { Banyak } \\
\text { Perlakuan }\end{array}$ & Volume Pelarut & Hasil Ekstrak & Rendemen \\
\hline n-Heksana & 7 kali & 49 liter & 18 gram & $0,56 \%$ \\
Etil asetat & 7 kali & 42 liter & 28 gram & $0,87 \%$ \\
Metanol & 3 kali & 12 liter & 3 gram & $0,09 \%$ \\
\hline
\end{tabular}

Tabel 2. Hasil uji kemurnian senyawa $\beta$-sitosterol pada plat KLT 


\begin{tabular}{|c|c|c|c|c|c|}
\hline \multirow{3}{*}{ Senyawa } & \multirow{3}{*}{ Perbandingan Eluen } & \multirow{3}{*}{$\mathrm{Rf}$} & \multicolumn{3}{|c|}{$\begin{array}{c}\text { Noda pada plat KLT dengan } \\
\text { Berbagai Penampak Noda }\end{array}$} \\
\hline & & & UV & UV & Pereaksi \\
\hline & & & $254 \mathrm{~nm}$ & $356 \mathrm{~nm}$ & $\begin{array}{l}\text { Lieberman- } \\
\text { Burchard }\end{array}$ \\
\hline \multirow{3}{*}{$\begin{array}{c}\beta- \\
\text { sitosterol }\end{array}$} & heksana : etil asetat (4:6) & 0,5 & - & - & 1 noda (Biru) \\
\hline & heksana : etil asetat $(3: 7)$ & 0,55 & - & - & 1 noda (Biru) \\
\hline & heksana : etil asetat (2:8) & 0,6 & - & - & 1 noda (Biru) \\
\hline
\end{tabular}

Berdasarkan Tabel 2, menunjukkan bahwa senyawa $\beta$-sitosterol telah murni, karena menunjukkan satu noda tunggal dan setelah direaksikan dengan pereaksi Lieberman-Burchard terdapat noda biru yang menandakan senyawa golongan steroid. (Chaturvedula, 2012)

\section{Karakterisasi $\boldsymbol{\beta}$-sitosterol}

Senyawa isolasi berbentuk serbuk putih dengan titik leleh 138$139^{\circ} \mathrm{C}$, serapan UV $\lambda_{\max }(\mathrm{MeOH})$ pada Data pergeseran kimia senyawa hasil isolasi ini dibandingkan data senyawa $\beta$-sitosterol yang diperoleh oleh Chaturvedula (2012). Tabel data ${ }^{13} \mathrm{C}$ dan ${ }^{1} \mathrm{H}$ NMR dapat dilihat pada Tabel 3. Dari data Tabel 3. ${ }^{1} \mathrm{H}$ dan ${ }^{13} \mathrm{C}$ NMR senyawa isolasi, pergeseran kimianya hampir sama dengan $\beta$-sitosterol. Dengan demikian diduga senyawa isolasi merupakan senyawa $\beta$ sitosterol.

Pergeseran kimia karbon antara 0 s/d 230 ppm yang terbagi atas karbon sp3 antara $\delta 0 \mathrm{~s} / \mathrm{d} 60$ ppm, karbon yang mengikat alkohol 60 s/d 80 ppm, karbon sp antara $70 \mathrm{~s} / \mathrm{d} 80$ ppm, karbon sp2 antara 100 s/d 160 ppm, panjang gelombang $207.8 \mathrm{~nm}$ yang menunjukkan transisi elektron dari $\pi \rightarrow$ $\pi^{*}$ dari ikatan rangkap yang tidak berkonjugasi. Karakterisasi senyawa isolasi dilakukan dengan spektrofotometer IR memperlihatkan beberapa serapan penting pada $\mathrm{V}_{\text {maks }}$ $\left(\mathrm{cm}^{-1}\right), 3420,65(-\mathrm{OH}), 2940,70(\mathrm{C}-\mathrm{H})$, 1977,77 (C=C). Spektrum UV dan IR senyawa $\beta$-sitosterol ditunjukkan pada Gambar 1 dan 2.

gugus karbonil dari gugus karboksilat, ester, lakton, amida, anhidrida, antara 160-180 ppm sedangkan aldehid antara 180 s/d 200 ppm dan keton antara 190 s/d 230 ppm (Santoni, 2009). Spektrum ${ }^{13} \mathrm{C}$ NMR pada Gambar 3. terdapat 29 sinyal pada $\delta 12,04 \mathrm{~s} / \mathrm{d}$ 140,93 ppm. Pada $\delta$ 140,93 dan 121,91 ppm masingmasing C5 dan C6 dengan ikatan rangkap dengan hibridisasi sp2. Pada $\delta$ 71,99 ppm adanya gugus C3 dengan mengikat alkohol sehingga pergeserannya jauh dari TMS. Pada $\delta$ $12,04 \mathrm{~s} / \mathrm{d}$ 57,04 ppm adanya karbon metil, metilen dan metin dengan hibridisasi sp3. 
Tabel 3. ${ }^{13} \mathrm{C}$ dan ${ }^{1} \mathrm{H}$ NMR senyawa $\beta$-sitosterol dan senyawa $\beta$-sitosterol (liteartur)

\begin{tabular}{|c|c|c|c|c|}
\hline \multirow{2}{*}{ Posisi atom C } & \multicolumn{2}{|c|}{ Senyawa Steroid hasil Isolasi } & \multicolumn{2}{|c|}{ Senyawa $\beta$-sitosterol } \\
\hline & ${ }^{1} \mathrm{H}(\mathrm{ppm})$ & ${ }^{13} \mathrm{C}(\mathrm{ppm})$ & ${ }^{1} \mathrm{H}(\mathrm{ppm})$ & ${ }^{1} \mathrm{C}(\mathrm{ppm})$ \\
\hline 1 & & 37,42 & & 37,5 \\
\hline 2 & & 29,30 & & 31,9 \\
\hline 3 & $3,52,(1 \mathrm{H}, \mathrm{m})$ & 71,99 & $3,53,(1 \mathrm{H}, \mathrm{m})$ & 72,0 \\
\hline 4 & & 42,48 & & 42,5 \\
\hline 5 & $5,35,(1 \mathrm{H}, \mathrm{m})$ & 140,93 & $5,36,(1 \mathrm{H}, \mathrm{m})$ & 140,9 \\
\hline 6 & & 121,91 & & 121,9 \\
\hline 7 & & 32,07 & & 32,1 \\
\hline 8 & & 31,83 & & 32,1 \\
\hline 9 & & 50,29 & & 50,29 \\
\hline 10 & & 36,68 & & 36,68 \\
\hline 11 & & 21,52 & & 21,3 \\
\hline 12 & & 39,94 & & 39,9 \\
\hline 13 & & 42,50 & & 42,6 \\
\hline 14 & & 57,04 & & 56,9 \\
\hline 15 & & 26,21 & & 26,3 \\
\hline 16 & & 28,44 & & 28,5 \\
\hline 17 & & 56,94 & & 56,3 \\
\hline 18 & & 36,33 & & 36,3 \\
\hline 19 & $0,92(3 \mathrm{H}, \mathrm{d})$ & 19,20 & $0,93(3 \mathrm{H}, \mathrm{d})$ & 19,2 \\
\hline 20 & & 34,11 & & 34,2 \\
\hline 21 & & 26,21 & & 26,3 \\
\hline 22 & & 46,00 & & 46,1 \\
\hline 23 & & 23,52 & & 23,3 \\
\hline 24 & & 12,16 & & 12,2 \\
\hline 25 & & 28,44 & & 29,4 \\
\hline 26 & & 20,01 & & 20,1 \\
\hline 27 & & 19,59 & & 19,6 \\
\hline 28 & $0,67,(3 \mathrm{H}, \mathrm{s})$ & 18,96 & $0,68(3 \mathrm{H}, \mathrm{s})$ & 19,0 \\
\hline 29 & $1,01(3 \mathrm{H}, \mathrm{s})$ & 12,04 & $1,01(3 \mathrm{H}, \mathrm{s})$ & 12,0 \\
\hline
\end{tabular}

Data proton ${ }^{1} \mathrm{H}$ NMR (pada Gambar 4). terdapat 50 proton yang terdeteksi. Pada $\delta 5,35$ ppm yang terdeteksi proton alkena dengan pergeseran terjauh dengan splitting multiplet. Pada $\delta 3,52$ ppm adanya pergeseran proton alkohol. Pada $\delta 0,69$, dan 1,01 ppm ada dua metil dengan splitting singlet. Pada $\delta 0,82,0,84$, dan 0,92 ppm ada tiga metil dengan splitting doblet. 


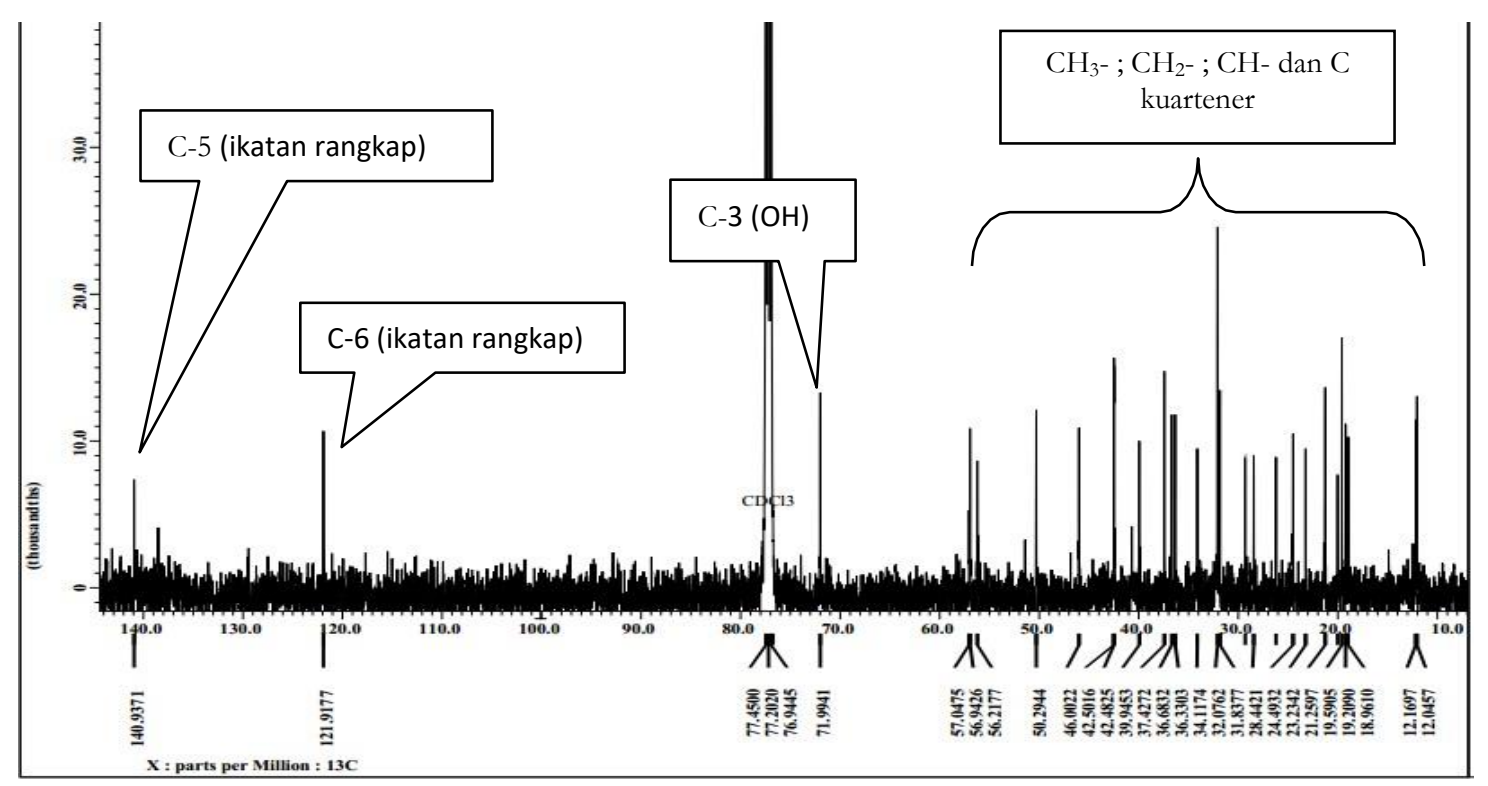

Gambar 3. Spektrum ${ }^{13} \mathrm{C}$ NMR senyawa isolasi ( $\beta$-sitosterol)

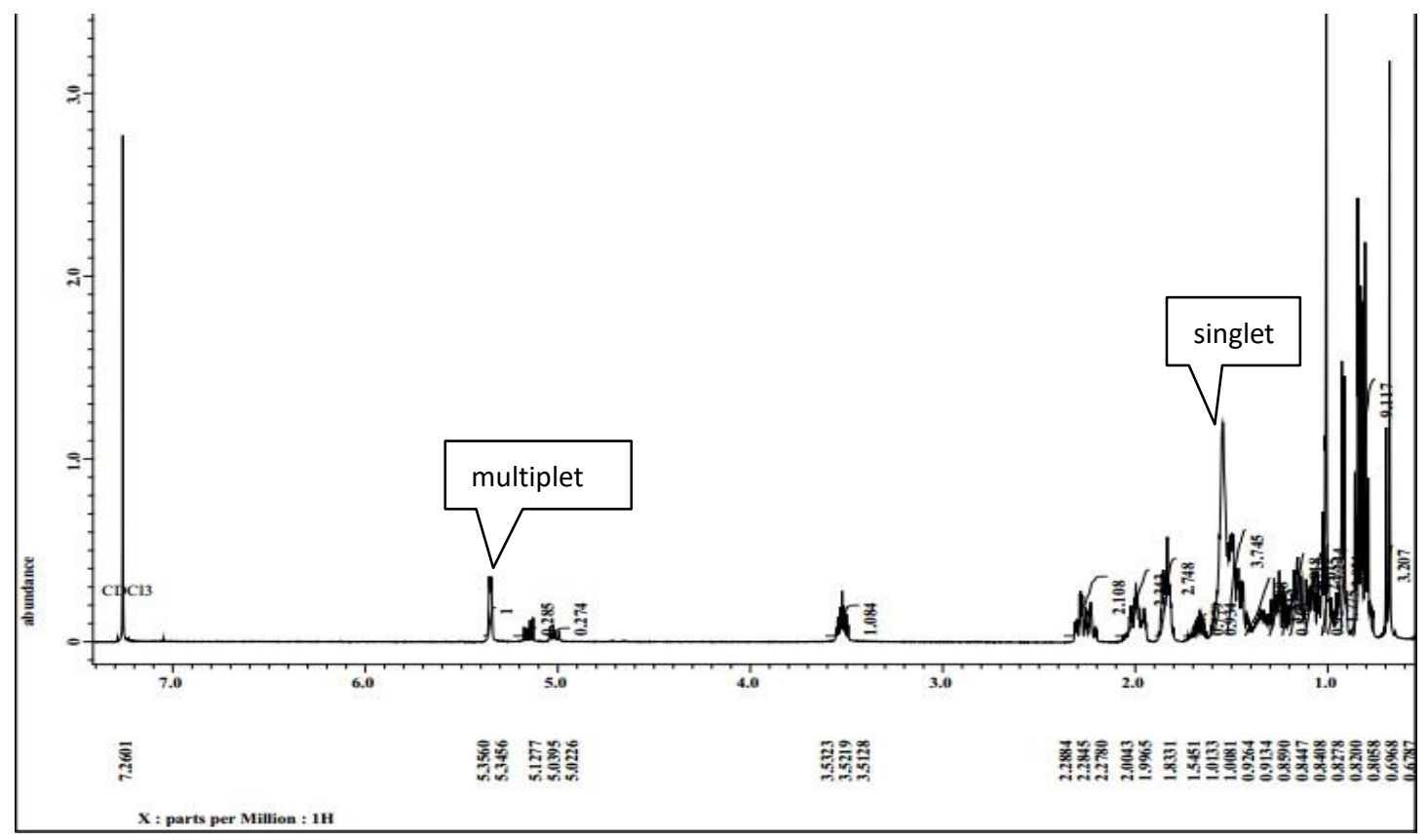

Gambar 4. Spektrum ${ }^{1} \mathrm{H}$ NMR senyawa isolasi ( $\beta$-sitosterol) 


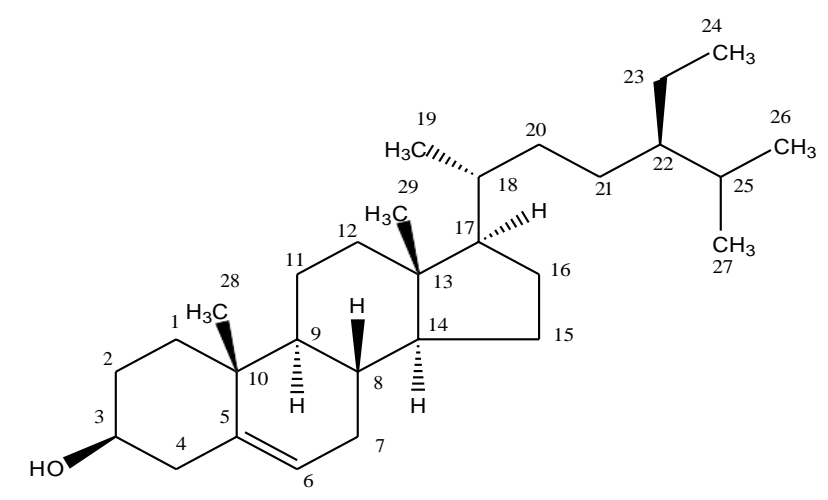

Gambar 5. Struktur senyawa isolasi (Senyawa $\beta$-sitosterol)

\section{Karakterisasi Senyawa Flavonoid}

Senyawa isolasi berbentuk putih kekuningan, pada UV-Vis memperlihatkan adanya serapan pada panjang gelombang maksimum, UV $\lambda_{\max }(\mathrm{MeOH}) 290,0 \mathrm{~nm}$ (pita I) dan 249,60 nm (pita II). Ini berarti senyawa hasil isolasi II mempunyai ikatan rangkap konyugasi dan memperlihatkan dua puncak yang khas untuk golongan senyawa flavanoid. Hasil spektroskopi infra merah, adanya gugus - $\mathrm{OH}$ alkohol pada bilangan gelombang $3374,36 \mathrm{~cm}^{-1}$. Pada bilangan gelombang 1244,74 $\mathrm{cm}^{-1}$ diindikasi adanya ulur C-O. Pada bilangan gelombang 2877,91 $\mathrm{cm}^{-1}$ diindikasi adanya C-H alifatik. Serapan pada bilangan gelombang $1459,41 \mathrm{~cm}^{-1}$ adanya $\mathrm{C}=\mathrm{C}$ aromatis. Pada bilangan gelombang $1665,38 \mathrm{~cm}^{-1}$ mengindikasi adanya $\mathrm{C}=\mathrm{O}$ keton. Hasil cyanidin test menunjukkan positif uji flavonoid dengan menghasilkan warna merah muda.

Struktur senyawa isolasi II yang diduga sebagai flavonoid tidak dapat ditentukan karena diperlukan data pendukung lainnya yaitu data hasil analisa spektroskopi NMR.

\section{KESIMPULAN}

Karakterisasi senyawa hasil isolasi dari ekstrak kulit batang pacar cina menggunakan UV, IR, 1H-NMR, dan 13C-NMR. Senyawa yang diperoleh dari kulit batang Aglaia odorata L yaitu $\beta$-sitosterol dan senyawa flavonoid.

\section{DAFTAR KEPUSTAKAAN}

Chaturvedula Venkata Sai Prakash Indra Prakash 2012. Isolation of Stigmasterol and $\beta$-Sitosterol from the dichloromethane extract of Rubus suavissimus. International Current Pharmaceutical Journal 2012, 1(9): 239-242

Dwi. D.D, Mai Efdi and Adlis Santoni (2015), Isolation and elucidation structure major compoundsfrom the leaves of Aglaia odorata Lour, Journal of Chemical and Pharmaceutical Research, 2015, 7(8):121-123 
Hartanto Satrio, Nurul Hidajati. 2012.

Isolasi dan Identifikasi Senyawa Terpen dari Ektrak Kulit Batang Aglaia odorata Lour (Meliaceae). UNESA Journal of Chemistry Vol. 1, No. 1. Surabaya.UNESA

Santoni, A. 2009. Elusidasi Struktur Senyawa Metabolit Sekunder Kulit Batang Surian (Toona sinensis) Meliaceae dan Uji Aktivitas Insektisida.

Disertasi.Program Pascasarjana Universitas Andalas. Padang.

Setiawati Wiwin, dkk. 2008. Tumbuhan Bahan Pestisida Nabati dan Cara Pembuatannya untuk Pengendalian Organisme Pengganggu Tumbuhan (OPT). Bandung : Balai Penelitian Tanaman Sayuran

Simes, J. J. H., J. G. Tracey, L. J. webb, and W. J. Dunstan. (1995). An Australian Phytochemical Survey. Commonwealth Scientific and Industrial Research Organization.

Sugijanto, N.E. Beatrice Yodianto, Made N. Kusumajaya, Noor C. Zaini. Aktivitas Antimikroba Dan Analisis Klt-Densitometri Metabolit Fraksi -Fraksi Ekstrak Endofit Dari Aglaia odorata. Berkala Ilmiah Kimia Farmasi, Vol.3 No. 1 Juni 2014

Zhang Heng, et. al 2012. Chemical constituents from Aglaia odorata Lour. Biochemical Systematics and Ecology. Elsivier 